\title{
Becoming an exhausted smoker: the beginning of the end
}

\author{
Khaldoun M. Aldiabat ${ }^{1, *}$, Michael Clinton ${ }^{2}$ \\ ${ }^{1}$ School of Nursing, University of Northern British Columbia, University Way, Prince George- BC, Canada \\ ${ }^{2}$ Rafic Hariri School of Nursing, American University of Beirut, Riad El-Solh, Beirut, Lebanon
}

\section{Email address:}

aldiabat@unbc.ca (K. M. Aldiabat),mc42@aub.edu.lb (M. Clinton)

\section{To cite this article:}

Khaldoun M. Aldiabat, Michael Clinton. Becoming an Exhausted Smoker: the Beginning of the End, American Journal of Nursing Science. Vol. 2, No. 1, 2013, pp. 6-13. doi: 10.11648/j.ajns.20130201.12

\begin{abstract}
There is a high smoking rate among male psychiatric nurses in Jordan and among psychiatric patients in general. Smoking addiction inhibits nurses from helping patients with smoking cessation. A better understanding of the smoking behaviors of male Jordanian psychiatric nurses is required if they help patients with smoking reduction and smoking cessation. This article reports the findings from a classical grounded theory study that explains why male Jordanian psychiatric nurses are not ready for a smoking cessation role. Analysis of the statements made by eight Jordanian psychiatric nurses during individual interviews identified the last phase in a psychosocial theory of the smoking trajectory of the smoking behaviors of these nurses, the contextualizing smoking behaviors over time theory. This phase explains eight categories describe the challenges involved in quitting. We conclude that local contextual challenges to quitting need to be understood if smoking reduction and cessation programs are to be effective.
\end{abstract}

Keywords: Addiction, Grounded Theory, Male Jordanian Psychiatric Nurses, Smoking Cessation, Symbolic Interactionism, Transtheortical Model

\section{Introduction}

Smoking among Jordanians is one of the most responsible factors for $42 \%$ and $13 \%$ of deaths in Jordan because of cardiovascular diseases and cancer respectively ${ }^{1}$. Despite this fact, the prevalence of smoking among male Jordanian nurses is still surprisingly the highest in comparison with other nurses around the world. The smoking rate among Jordanian male nurses was three times higher than the smoking rate among female nurses -- $49 \%$ and $17 \%$ respectively ${ }^{2}$. Another study conducted by Shishani, Nawafleh, and Froelicher ${ }^{3}$ showed that the smoking rate among general Jordanian nurses was $41.5 \%$ and significantly more male nurses smoked more than female nurses. Although smoking rate among Jordanian psychiatric nurses was not studied, it is expected that they smoke in same rate or more than other general nurses because of their own smoking behavior and as a result of inhaling smoke from the mental health patients who smoke.

Smoking prevalence is high among psychiatric nurses and people with a history of mental illness compared to the general population ${ }^{4-6}$. Psychiatric nurses play a salient role in smoking cessation and prevention programs to promote health for smokers as a part of their health promotion role ${ }^{7}$.
Although they pride themselves on holistic care and for relying in practice on biopsychosocial models ${ }^{8}$ of care, psychiatric nurses who smoke have not yet acknowledged that one of their primary roles is to inform patients of the value of smoking cessation and smoking prevention programs ${ }^{9-11}$. Although smoking with patients influence negatively the image of nurses as role models for healthy practices, $50 \%$ of psychiatric nurses have a belief that smoking with patients improves the therapeutic relationship between nurses and their patients ${ }^{1}$.

High rates of smoking among psychiatric nurses have been identified as the most significant barrier that prevents them engaging with smoking related health promotion programs for patients in psychiatric settings ${ }^{12}$. Previous studies have shown that the personal smoking behaviors of nurses not only affect their personal health, but also their attitudes to smoking related health promotion and counseling ${ }^{13-15}$. Nurses who smoke are less motivated to provide smoking cessation support for patients and underestimate the health risks of smoking ${ }^{16,17}$.

Although many studies have insisted on the salient role of nurses in smoking cessation programs, little attention has been given to helping nurses who smoke to quit ${ }^{18,19}$. Rowe and Clark ${ }^{13}$, have reported that nurses need smoking cessation programs to help them quit smoking as a prerequisite 
for helping patients to cut down or quit. A better understanding of determinants of smoking cessation is needed to provide more effective smoking cessation programs ${ }^{20}$. The need is particularly urgent in countries such as Jordan that have high smoking rates ${ }^{21}$ and few smoking cessation programs $^{21-23}$. According to Al-Matubsi et al. ${ }^{24}$, although $50 \%$ of Jordanians are classified as regular smokers, there is no specialized smoking cessation and prevention programs in Jordan to alert population regarding smoking risks and benefits of quitting. These programs have to take in consideration all social, legal, and economical smoking determinants in order to empower population to take the right decision on the right time to quit smoking or to not engage in this behavior at all ${ }^{1,24}$.

Schultz ${ }^{25}$ identified nurses who smoke as a unique group who must be helped to quit smoking. A better understanding of the challenges that influence nurses to smoke and their reasons for quitting is essential if this goal is to be achieved. According to Schultz ${ }^{25}$, the methodological limitations of quantitative studies have inhibited this understanding. Therefore, qualitative studies are needed to afford a deep understanding of the factors and challenges involved in addressing the smoking behaviors of nurses. There is a particular need to better understand how nurses who smoke incorporate professional knowledge about health into their role as health care workers ${ }^{25}$.

Because little is known about smoking behavior among Jordanian psychiatric nurses, how they feel toward theirs selves and how they perceive their smoking behavior after long time of smoking, the purpose of this paper is to explain what male Jordanian psychiatric nurses mean when they describe themselves as "exhausted smokers", to describe how they engage with being an exhausted smoker, and to explore how being an exhausted smoker affects their ability to help patients with smoking cessation. More specifically, we describe becoming an exhausted smoker as the final phase in our contextualizing smoking behavior over time theory. This theory was the generated substantive grounded theory from data collected from eight male Jordanian psychiatric nurses to understand their smoking behavior. The previous phases in this theory are: becoming a novice smoker becoming a formal smoker and becoming a heavy smoker. We present the final phase in our grounded theory of smoking behaviors here because our data is so rich that it the complete theory defies description within the scope of one article. As a result, we focused on what meanings the participants gave to smoking after long time of smoking, and how those meanings changed over time. In this article we are concerned only with these final and current meanings. We emphasized to discuss and relate this phase with perspectives of symbolic interactionism and transtheoretical model.

\section{The Method}

This section summarizes the research method which was employed in the main study. A detailed report of the re- search method, data analysis, study context, research ethics, and trustworthiness can be found in Aldiabat and Clinton ${ }^{26}$ [22] published paper: [Contextualizing smoking behaviour over time: A smoking journey from pleasuring to suffering.]. A qualitative method was chosen to conduct the main study using the classical grounded theory approach ${ }^{27}$. The main study was conducted in Amman (capital of Jordan) between 2009-2010 after approved health research ethics committees in both Canada and Jordan. Data were collected from a theoretical sample of eight male psychiatric nurses who smoked and worked in a psychiatric hospital using semi-structured interviews, non-participant observation, and field notes. The constant comparative method of data analysis was used thus, data collection, coding and analysis occurred simultaneously. Strategies were used throughout the study to ensure trustworthiness that is, fulfill the requirements for credibility, transferability, dependability and confirmability.

\subsection{Becoming an Exhausted Smoker}

This psychosocial process describes how over 10 to 20 years male Jordanian psychiatric nurses become exhausted by their smoking behavior and need help to quit. With one exception, the participants continued to contextualize their smoking habits not by using the word addiction, which in Arabic culture is reserved for use of heavy recreational drugs and alcohol but by simply indicating the desire to stop smoking. In figure 1, the nurses described eight factors that contextualize this phase in their smoking addiction .

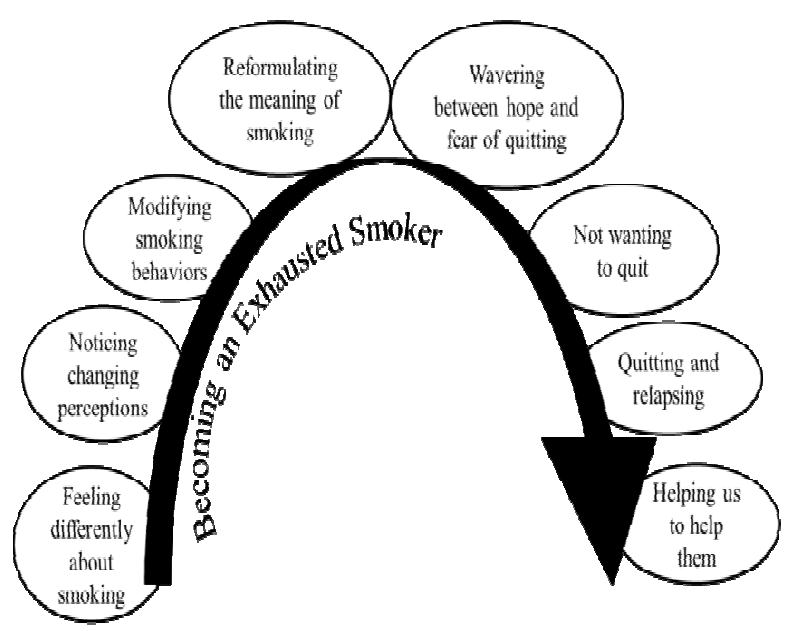

Figure 1. Becoming an Exhausted Smoker Subcategories.

(a) Feeling differently about smoking

(b) Noticing changing perceptions

(c) Modifying smoking behaviors

(d) Reformulating the meaning of smoking

(d) Wavering between hope and fear of quitting and

(e) Not wanting to quit

(f) Quitting and relapsing

(g) Helping us to help them 


\subsubsection{Feeling Differently about Smoking}

The participants reported changing over time the meanings they gave to smoking that is, in how their current feelings about smoking differ from those they had when they started smoking. The overall sense of what the nurses felt about smoking when they were interviewed in (2010) can be best described as "exhausted". Their exhaustion describes feelings associated with having lost pleasures and enjoyment initially associated with smoking as the result of becoming mindful of changed societal attitudes towards smokers through the increasingly assertive behaviors of non-smokers. Four senses of exhaustion can be described see Table 1:

Table 1. Feeling different about smoking.

\begin{tabular}{ll}
\hline Category & Becoming an Exhausted Smoker \\
\hline Sub-category & Feeling differently about smoking \\
& Feeling nervous \\
indicators & $\begin{array}{l}\text { Feeling sad, to blame, and uncertain } \\
\text { Feeling the disgust of others } \\
\end{array}$ \\
& Feeling challenged \\
\hline
\end{tabular}

Feeling nervous

At first, I experienced relaxation when I was smoking (...). When I smoke now, I feel nervous so I smoke more to get rid of that feeling (...). When I light up, I feel relaxed but only for a short time then I feel nervous again and stressed (Yasser).

Feeling sad, to blame and uncertain

After many years of smoking, I am feeling sad because my smoking is going to kill me and harm my family members (...). I blame myself because I have tried to quit many times. I relapse shortly after each attempt (...). I don't know what's going on inside me. (Osama)

Feeling the disgust of others

Sometimes, I close my eyes and imagine how disgusting I am because I smoke (...). I feel that my wife doesn't like me to kiss her because smell of smoke (....). She [his wife] does not tell me that my mouth smells disgusting, but I imagine that's how she feels (...). I think other people are disgusted by my smoking. This is also how I feel about myself now (Ismael).

Feeling challenged

I am really living a challenging battle with smoking (...). By nature, I like challenges and I like to be the victor all the time. I don't know why I am losing this battle [the battle to give up smoking] I feel like someone who has a sharp knife stuck in his throat (...). He will be injured no matter whether he pulls it out or swallows it (...).I can't quit and I am uncomfortable about continuing [to smoke] (Mustafa).

\subsubsection{Noticing Changing Perceptions}

The participants stated that changes in their feelings about smoking were associated with awareness of changing societal attitudes towards smokers. This does not mean that the participants were influenced by these changes in societal perceptions alone the unchanging perceptions of fellow smokers were salient as well:

I do not think smokers perceive my smoking habits any differently now than before (...). They perceive me normally when they know I am a smoker and a psychiatric nurse. I do not change my smoking behavior for them. I continue smoking just like them. The message that I am going to give to you is this: whatever smokers' backgrounds, smoking unites us and normalizes our perceptions of each other (Kamal).

The pressure to quit smoking comes from sensitivity to but not necessarily acceptance of changing societal attitudes towards smokers mediated through the comments and behaviors of non-smokers. Common reactions to smokers attributed by the nurses to non-smokers include undesirability, negativity and unprofessionalism, and nauseating (see Table 2):

Table 2. Noticing Changing Perception.

\begin{tabular}{ll}
\hline Category & Becoming an Exhausted Smoker \\
\hline Sub-category & Noticing Changing Perception \\
& Undesirability \\
& $\begin{array}{l}\text { Negativity } \\
\text { indicators }\end{array}$ \\
& Unprofessionalism \\
& Nauseating \\
\hline
\end{tabular}

Undesirability

Recently, I noticed that people are becoming brave enough to ask smokers not to smoke (...). You know, some people ask you very politely and in a gentle manner to stop smoking, or to smoke in another area. Other people are more aggressive. They give you non-verbal cues to stop smoking and put you in a situation where you hate yourself $(\ldots)$. This makes me feel I am an undesirable person. So I check out the situation carefully before I smoke in front other people in many instances I ask for permission first (Aladdin).

Negativity and unprofessionalism

I think they [non-smokers] judge us [smokers] negatively as people with an unhealthy habit (...). It may be difficult for them to understand how nurses are prepared to damage their health by smoking (...). I think they [non-smokers] associate smoking with the image they have of nurses (...). They think that a nurse who smokes is unprofessional, but I am a professional nurse [emphasis added] (...). I don't know how smoking influences professional status (...). Smoking is a personal option for me and does not affect my job (...). I do my job perfectly (Hassan).

\section{Nauseating}

Many non-smokers perceive people who smoke as nauseating. They totally reject smoking because it is harmful to health (...). Unfortunately, smokers are seen as a nuisance (...). Non-smokers can see us as they wish, but we would prefer not to know how they see us (...). For example, a new friend of mine invited me to visit him in his house. It was the first time I had been to his home. When I rang the intercom, I was surprised to hear a recorded message that welcomes 
guests and thanks them for not smoking inside the house (...). That message made me feel unwelcome because I am a smoker (...). I felt like a person with a communicable disease someone for non-smokers to avoid because I am sick (Mohammed).

\subsubsection{Modifying Smoking Behaviors}

Although the participants were ambivalent about the influence of non-smokers, which they interpreted as restrictive, they nonetheless developed personal descriptions of their smoking behaviors that were sympathetic to negative social stereotypes of smokers. They change their smoking behavior frequently based on how non-smokers look and perceive them. They described their personal smoking habits as (see Table 3):

Table 3. odifying Smoking Behavior.

\begin{tabular}{ll}
\hline Category & Becoming an Exhausted Smoker \\
\hline Sub-category & Modifying Smoking Behavior \\
& Shameful \\
indicators & Disrespectful \\
& Nuisance \\
& Selfish \\
\hline
\end{tabular}

Shameful: "It is shameful to force others to inhale my cigarette smoke" (Mustafa)

Disrespectful: "They [non-smokers] may think I don't respect them" (Ismael)

Nuisance: "I may bother people by spoiling their access to fresh air" (Aladdin)

Selfish: "I see myself as a selfish person when I smoke in front of non-smokers" (Kamal) and Empathy: "I put myself in their [non-smokers] shoes" (Mohammed).

The sense in which the participants use the word "exhaustion" can now be qualified. "Exhaustion" refers to the weariness associated with forever trying to balance the personal desire to smoke in opposition to the preferences of non-smokers with the need to accommodate the wishes of non-smokers sufficiently to avoid embarrassment or conflict. That is the need to balance a strongly felt right to smoke with "keeping the peace with non-smokers":

Really, I am tired because I do not know how to deal people who dislike smoking (...). I fluctuate between smoking whenever I want and hiding my smoking from non-smokers (...). I want to smoke when I want to, and not be told not to smoke. I don't want to be controlled by the preferences of others, but to some extant I am (Hassan).

\subsubsection{Reformulating Meanings}

The participants reformulated meanings of smoking to fit more consistently with the pressures they experienced from non-smokers. The new meanings they gave to smoking were distinctly negative:

Smoking changes from a habit, to recurrent habit, to a disgusting habit, to a dangerous habit (...). It damages health, costs too much money and is no longer pleasurable
(...). I'm convinced that smoking moves the smoker from a good healthy life to a miserable one (...). I think it is the time to announce that becoming a smoker involves deceiving oneself about the consequences (Osama).

Smoking is an addiction. I didn't think I would become addicted but I am (...). I hate my self due to my smoking addiction (...). When I smoke, I feel selfish because all that matters is how to enjoy myself (...). After each cigarette I blame myself for smoking. I reproach myself for smoking in front of my family and kids. I don't want my addiction to make them sick (Kamal).

\subsubsection{Wavering between Hope and Fear}

All eight participants reported ambivalent feelings about smoking. They were somewhat disgusted that they are addicted to smoking and some want to quit, but at the same time they are not, as they put it, "brave enough" to take this step.

The ambivalence at the center of exhaustion reported by the participants has two aspects hoping and fearing (see Table 4). Hoping involves:

Table 4. Wavering between Hope and Fear.

\begin{tabular}{|c|c|}
\hline Category & Becoming an Exhausted Smoker \\
\hline \multirow[t]{2}{*}{ Sub-category } & Wavering between Hope and Fear \\
\hline & $\begin{array}{l}\text { Hoping involves: } \\
\text { Having a desire to quit } \\
\text { Feeling bad about smoking } \\
\text { Feeling helpless }\end{array}$ \\
\hline \multirow[t]{2}{*}{ indicators } & Feeling challenged \\
\hline & $\begin{array}{l}\text { Fearing involves: } \\
\text { Fear of withdrawal symptoms } \\
\text { Fear of identity loss }\end{array}$ \\
\hline
\end{tabular}

Having a desire to quit: "I have a strong desire to quit smoking if not today than tomorrow..." (Yasser)

Feeling bad about smoking: " ...I do not like it [smoking] any more (...). Cigarettes are a disgusting product. I am looking forward to becoming free of smoking one day (...)."

Feeling helpless: “(...) Oh! Man, I am really tired of smoking. I hope one day to get the motivation to quit [smoking]" (Hassan)

Feeling challenged: "Smoking is a very complex problem that I want to solve" (Aladdin) and Being addicted: “...It [smoking] is an addiction problem. I realize that I need medical assistance to quit" (Kamal).

Fearing involves:

Fear of withdrawal symptoms: "...I heard that the withdrawal symptoms are intolerable, and I am not brave enough to quit. Yes, I am a too cowardly to take a step like that [quit smoking]..." (Osama)

Fear of identity loss: “(...) Smoking has become an important part of my identity it shadows me everywhere and at all times (...). I fear part of me will be lost if I quit" (Yasser) and Fear of no alternative: "Oh Man, I cannot even imagine myself without cigarettes. I am used to holding the cigarette, 
the cigarette box and the lighter (...). I am not sure what I would do with my hands if I quit" (Ismael).

\subsubsection{Not Wanting to Quit}

Despite the weariness of exhaustion, not all of the participants wanted to quit, typically because of the difficulties involved, but also due to the loss of secondary gains such as the ability to use smoking as justification for a break from work:

"I have no intention of quitting [smoking]" (Hassan)

" it would be difficult to quit smoking because there are no smoking cessation programs here [in this psychiatric setting]" (Kamal)

"it is difficult to quit smoking because the nothing here [in the hospital] encourages quitting" (Ismael)

" it is difficult to quit smoking because this workplace is stressful and there are no other ways to manage stress here [psychiatric setting]" (Hassan)

"I don't want to lose these valuable extra work breaks for smoking" (Ismael) and,

"Thinking about quitting is impossible because the presence of other smokers encourages me to smoke more" (Hassan).

\subsubsection{Quitting and Relapsing}

Five participants described how they were thinking seriously about quitting smoking or how they had tried to quit and had relapsed:

"I am thinking seriously about quitting soon. I will try to quit this Ramadan" [Ramadan is the fasting month for Muslims it was two months away at the time of the interview] (Osama)

"I need to quit but I hesitate to now because I need more social support. I have financial problems that need to be solved first, and the workplace is not encouraging me to quit smoking. But, I am thinking seriously about quitting" (Mohammed)

Actually, I cannot balance my desire to smoke and fears of quitting with my needs and the needs of others (...). I tried to quit to restore my health and to save money, but I also wanted to protect our kids from engaging in smoking...becoming smokers (...). Although I don't smoke in front of my kids, I was shocked when I saw my 5-year old imitate smokers by putting a straw between his fingers and puffing on it like a cigarette. The problem is that every time I try to quit I cannot last more than three days. I find myself smoking again because I fear becoming a non-smoker. This is because my co-workers, brothers, friends, and neighbors convince me that there is no enjoyment in life without a cigarette and a cup of coffee (...) But I still think about quitting. (Yasser)

I hope I can find a solution (...). Actually, I stopped smoking for about five months (...). I decided to quit when I had some health problems [chest pain not related to cardiac problems], but I relapsed because there were stressful events involving the family. I also had a negative experience with withdrawal symptoms [headache, anger feelings of guilt craving loss of concentration] (Mustafa) and,
Yes, I wish I could stop smoking before tomorrow [immediately]. However, quitting smoking is not the decision of an individual it needs collaboration with those around me. In the same way I needed encouragement to start smoking, I need encouragement to stop (Aladdin).

\subsubsection{Helping Us to Help Them}

Three participants including stated that they needed help with their own smoking habit before they would be able to help patients with smoking cessation:

"They [ administrators] must stop giving advice by sending letters about smoking prohibition rules instead, they must provide some real action to help us stop smoking" (Mustafa)

"Psychiatric nurses must stop distributing cigarettes to patients" (Yasser)

" a real smoking prohibition enforcement program is needed because smoking cessation has to be more than ink on the paper" (Aladdin) and,

Smoking cessation programs must be suitable for the workplace culture. Such hinges as designated smoking areas for staff and patients must be considered. Other areas such as dining areas, nursing stations, and dayrooms and bedrooms should be smoke free. Such measures would help with the major causes of smoking in the workplace [no smoking prohibition policy, and the ready availability of cigarettes] ( Mustafa).

In summary, the participants recontextualized their smoking behaviors over time. The process involved changing positive feelings about smoking to negative self-attributions associated with changing societal attitudes towards smokers as mediated by the assertiveness of non-smokers. These changes were associated with perceiving smoking less as a pleasure and more as an addiction. The participants engaged with exhaustion in different ways. One participant stated flatly that he had no intention of quitting. Three participants referred to workplace factors that make it difficult to quit, implying that they, too, would continue smoking unless these factors changed. Two participants indicated that they were thinking seriously about quitting. Three participants described how they relapsed after trying to quit. Four participant stated that administrative action was required to help them quit, and that such action was a pre-requisite for helping patients to quit. That the eight participants engaged with exhaustion in more than eight ways indicates that the modes of engagement described are not mutually exclusive.

\section{Discussion}

The categories in the exhausted phase of the smoking trajectory of male Jordanian psychiatric nurses can be better understood by considering parallel concepts in the transtheortical perspective of addiction ${ }^{28}$ and insights from symbolic interactionism $^{29}$.

\subsection{The Transtheoretical Perspective}


The transtheoretical perspective on addiction, or stages of change model. was developed by Prochaska and DiClemente ${ }^{30}$ over three decades ${ }^{28,31,32}$ and has become an influential theoretical framework within the addiction behavior field. The model is a continuum of motivational readiness towards healthy or unhealthy behaviors, and consists in six stages: pre-contemplation, contemplation, preparation, action, maintenance, and relapse ${ }^{30,31}$. Although these stages are not linear, a transition from one stage to another takes place through the changes in cognitive and behavioral processes. The process of change is theorized to involve internal experiences and external activities in a specific context and benefits and costs associated with engaging in a particular behavior ${ }^{31}$ such as smoking.

According to DiClemente ${ }^{31}$, "once individuals complete the maintenance tasks required to incorporate an addiction into their lives, they leave the stage of becoming addicted and enter a pre-contemplation stage that can end in recovery. Therefore, it is appropriate to begin to understand addiction and the recovery [within the pre-contemplation] stage" (p. 44).

Some of the Jordanian psychiatric nurses implied that they were in what DiClimentie ${ }^{31}$ would regard as the contemplation stage of change because they were thinking seriously about quitting smoking. Others were in the pre-contemplation phase because they were continuing to find ways of maintaining their smoking habit. Those participants who were thinking about quitting hesitated to make a decision because they were, from a transtheoretical perspective) not sure that the benefits of quitting would exceed the costs. That is, those nurses wavering between hope and fear could not balance the pros and cons of smoking with those of quitting hence their dilemma. Although they had a desire to quit, the nurses feared withdrawal symptoms and the anticipated negative reinforcement provided strong motivation to continue smoking.

According to DiClemente ${ }^{31}$, changing one's substance use pattern involves engaging in conscious, cognitive and experiential activities. The Jordanian psychiatric nurses reported that they began to experience changes over time in: their feelings about smoking, the perceptions of others, especially non-smokers, in the meanings they gave to smoking, and in how they saw their saw their role as nurses with regard to helping patients quit smoking.

A noticeable finding is that those participants who were thinking seriously about smoking discussed the challenges of quitting from the perspective of what others should do. They indicated an external locus of control ${ }^{33}$ in that they put the onus for action in supporting staff to quit smoking on hospital administrators. The becoming an exhausted smoker phase leads not to readiness to assist patient to quit or at least cut down on smoking, but at best to either a contemplation phase that consists in hope and fear, or a desire for administrative action, neither of which provides a basis for smoking reduction or smoking cessation programs for staff or patients.

\subsection{Symbolic Interationism}

From the perspective of symbolic interactionism becoming an exhausted smoker involves social interaction with smokers and non-smokers. Interacting with smokers reinforces smoking addiction. Interaction with non-smokers prompts negative self-feelings which encourage either behaviors to maintain the smoking habit, such as smoking with other smokers, or changes in when and where the smoker chooses to smoke. Either strategy involves the smoker in taking the role of the generalized other ${ }^{29,34}$ that is, in taking into account the perceptions of non-smokers in general.

Reformulating the initial positive meaning of smoking to a more negative one, and awareness of the generalized perceptions of non-smokers do not explain how the participants became exhausted smokers. A broader conception of becoming an exhausted smoker was needed to take into account the process as a whole. The changes involved in the transition from being a regular smoker to being an exhausted smoker involve re-evaluation of feelings, experiences, self-concept and smoking behaviors. Readiness to help patients with smoking reduction and smoking cessation is an issue for only those male Jordanian psychiatric nurses who want to quit smoking but engaging with this needed health promotion role requires prior administrative action.

There is evidence that people change their behavior on the basis of attitudes, beliefs, and perceptions that are consistent with personal experiences, desired behaviors, perceptions of significant others and the generalized perceptions of social groups such as those depicted by references to non-smokers. Castrucci, Gerlach, Kaufman, and Orleans ${ }^{35}$ investigated the association between adolescents' smoking behaviors and their beliefs. These investigators reported that adolescents smoke because they believe smoking reduces stress, provides relaxation, and improves social relations.

Our study of male Jordanian psychiatric nurses showed that such beliefs do not last because societal perceptions and expectations change. As a result, a contextualizing smoking over time theory is needed to explain the factors associated with the smoking trajectory of male Jordanian psychiatric nurses.

Piko, Bak, and Gibbons ${ }^{36}$ investigated why people start smoking. They found that smokers are influenced by societal attitudes that perceive smoking as: cool, popular, smart, and independent. Non-smokers are more strongly influenced by negative societal images of smoking smokers are dull, immature, and childish. These findings led Piko, Bak, and Gibbons ${ }^{36}$ to recommend promotion of negative images of smokers to discourage smoking. Our study of male Jordanian psychiatric nurses implies that this strategy cannot be wholly effective because there are smokers who want to maintain their smoking habit and others who cannot take personal responsibility to quit. The Piko, Bak and Gibbons ${ }^{36}$ study was not designed to investigate how perceptions of smoking and of societal attitudes to smoking change over time. Our study enabled such changes to emerge from the data. 
Weinstein ${ }^{37}$ investigated how personal experience influences decisions to continue smoking or quit smoking. Weinstein concluded that negative personal experiences motivate behavioral change. For example, people who take up smoking because they believe it will reduce stress will be motivated to quit if they do not experience stress reduction. Our study implies something far more complex. The same societal and contextual factors can have different influences on smoking addiction. Smokers experiencing the same culture, the same work setting, and the same or similar everyday pressures can react in at least five ways: they can modify their behavior to reduce their addiction they can get stuck in the dilemma of hoping to quit while fearing the consequences they can think seriously about quitting, they can try to quit with all that implies for the possibility of relapse, or they can wait for others to do something to help them.. However, the latter will not necessarily lead to behavioral change. What matters is whether smokers feel they have the resources and support to quit. As a result male Jordanian psychiatric nurses who are smokers are unable to help their patients to quit smoking until they can get the help they need to overcome their own smoking addiction.

\section{Conclusion}

Male Jordanian psychiatric nurse smokers have much in common with the population of smokers in Jordan. However, they face unique smoking cessation challenges as a result of contextual factors in the work place. Psychiatric nurses in other countries may face similar challenges, but this does not mean the contextual factors involved are identical. Context matters and understanding the local cultural factors in psychiatric nursing practice settings is an essential first step in designing workplace appropriate smoking cessation assistance for psychiatric nurse smokers in Jordan and other Arabic speaking countries. Additional in-depth studies of local contextual factors that affect smoking behaviors in the workplace are required if psychiatric nurse smokers are to facilitate smoking reduction and smoking cessation. The need for such programs is pressing psychiatric hospitals and psychiatric units in Jordan. The contextual factors that affect the health promotion role of male Jordanian nursing working in community settings are a topic for future research. The smoking behaviors of female Jordanian psychiatric nurses and their implications for nurses and patients is another important future research topic.

\section{Endnote}

The terminology used to refer to people with a mental health problem or a mental disorder is controversial and differs among countries. In Jordan people with a mental health problem or mental disorder treated in psychiatric hospitals and psychiatric units are referred to as patients. Consequently, they are referred to as patients in this article. This does not mean the authors believe that the designation 'patient' is the most appropriate way to refer to people re- ceiving treatment and care in psychiatric hospitals or psychiatric units.

\section{References}

[1] Haddad1, L. G. Al-Zyoud, S. Baker, N. A. Gharaibeh, H. Shahawy, O. E. Alramadhani, R. (2011). Secondhand Smoking in Jordan: Clearing the Air for One of the Highest Tobacco Prevalence Countries in the Middle East. Tobacco Use Insights, 4, 1-7. doi: 10.4137/TUI.S6802.

[2] El-Khushman, H. M. Sharara, A. M. Al-Laham, Y. M. Hijazi, M. A. (2008). Cigarette smoking among health care workers at King Hussein Medical Center. Journal of Hospital Medicine, 3(3), 281-284. doi:10.1002/jhm .319.

[3] Shishani, K. Nawafleh, H. Froelicher, E. S. (2008). Jordanian Nurses' and Physicians' Learning Needs for Promoting Smoking Cessation. Progress in Cardiovascular Nursing, 23(2), 79-83. doi:10.1111/j.1751-7117.2008.07745.x.

[4] Dickens, G. L. Stubbs, J. H. Haw, C. M. (2004). Smoking and mental health nurses: a survey of clinical staff in a psychiatric hospital. Journal of Psychiatric and Mental Health Nursing, 11(4), 445-451. doi:10.1111/j.1365-2850.2004.00741.x.

[5] Meltzer, H. Gill, B. Petticrew, M. Hinds, K. (1996). Economic activity social functioning of residents with psychiatric disorders, OCP surveys of psycatric morbidility in Great Britin Report 6, London,HMS.

[6] Reilly, P. Murphy, L. Alderton, D. (2006) Challenging the smoking culture within a mental health service supportively. International Journal of Mental Health Nursing, 15(4), 272-278. doi:10.1111/j.1447-0349.2006.00434.x.

[7] Hancock, B. Hancock, D. G. (1993). Registered Mental Nurses' perceived role in health education about smoking. Health Education Journal, 52(2), 85-90.

[8] Boyd, M. A. (2008). Psychiatric Nursing: Contemporary Practice 4ed. Lippincott Williams \& Wilkins: Philadelphia.

[9] Cataldo, J. K. (2001). The role of advanced practice psychiatric nurses in treating tobacco use and dependence. Archives of psychiatric nursing, 15(3), 107-119.

[10] McCloughen, A. (2003). The association between schizophrenia and cigarette smoking: A review of the literature and implications for mental health nursing practice. International Journal of Mental Health Nursing, 12 (2), 119-129.

[11] Van Dangon J. C. (1999). SmoKing and persistent mental illness : An exploratory study. Journal of Psychosocial Nursing, 37 (11), 8.

[12] Froelicher, E. S. Kohlman, V. C. (2005). Tobacco Free Nurses: THE FACTS ON NURSES AND SMOKING. Journal of Cardiopulmonary Rehabilitation and Prevention, 25(4), 198-199.

[13] Rowe, K. Clark, J. M. (2000) The incidence of smoking amongst nurses: a review of the literature. Journal of Advanced Nursing, 31, (5), 1046-1053.

[14] Sperber, A. D. Geftler, A. Goren, M. Cohen, H. Levi, G. Raz, I. Mor, Z. Yachelevich, N. Malik, T. Shubin, A. Kachel, E. Perl, S. Steinberg, A. Sarov, B. Bearman, J. (1995). Medical 
students' contribution to the development of a smoke-free hospital policy in a university medical centre: a relevant learning experience. Medical Education, 29 (1), 43-47.

[15] Strobl, J. Latter, S. (1998). Qualified nurse smokers' attitudes towards a hospital smoking ban and its influence on their smoking behaviour. Journal of Advanced Nursing, 27(1), 179-188.

[16] McKenna, H. Slater, P. McCance, T. Bunting, B. Spiers, A. McElwee, G. (2001). Qualified nurses' smoking prevalence: their reasons for smoking and desire to quit. Journal of Advanced Nursing, 35 (5), 769-775.

[17] Willaing, I. Ladelund, S. (2004). Smoking behavior among hospital staff still influences attitudes and counseling on smoking. Nicotine \& Tobacco Research, 6(2), 369-375. doi:10.1080/14622200410001676422.

[18] Chalmers, K. Bramadat, I. J. Cantin, B. Murnaghan, D. Shuttleworth, E. Shannon, S.-F. Tataryn, D. (2001). A Smoking Reduction and Cessation Program with Registered Nurses: Findings and Implications for Community Health Nursing. Journal of Community Health Nursing, 18(2), 115-134. doi:10.1207/153276501300118 539.

[19] Sarna, L. Bialous, S. A. Wewers, M. E. Froelicher, E. S. Danao, L. (2005) Nurses, smoking, and the workplace. Research in Nursing \& Health, 28(1), 79-90. doi:10.1002/nur.20059.

[20] Freund, K. M. D'Agostino, R. B. Belanger, A. J. Kannel, W. B. Stokes, J., Predictors of Smoking Cessation: The Framingham Study. American Journal of Epidemiology 1992, 135(9), 957-964.

[21] Al-Motassem, Y. F. Bulatova, N. 1. AbuRuz, S., Management of Coronary Artery Disease in Jordan: Cross-Sectional Comparative Study. Jordan Journal of Pharmaceutical Sciences 2008, 1(1), 28-39.

[22] Abu-Baker, N. Haddad, L. Mayyas, O. (2010). Smoking Behavior among Coronary Heart Disease Patients in Jordan: A Model from a Developing Country. International Journal of Environmental Research and Public Health, 7(3), 751-764.

[23] Haddad, L. G. Malak, M. Z. (2002). Smoking habits and attitudes towards smoking among university students in Jordan. International journal of nursing studies, 39(8), 793-802. doi:10.1016/S0020-7489(02)00016-0.

[24] Al-Matubsi1, H. Y. Kanaan, R. A. Hamdan, F. Salim, M. Oriquat, G. A. Al-Hanbali5, O. A. (2011). Smoking Practices in Jordanian People and their Impact on Semen Quality and Hormonal Levels among Adult Men. Central European Journal of Public Health, 19 (1), 54-59.
[25] Schultz, A. S. H. (2003). Nursing and tobacco reduction: a review of the literature. International Journal of Nursing Studies, 40(6), 571-586. doi:10.1016/S0020-7489(03)00038-5.

[26] Aldiabat, K. Clinton, M. (2012). Contextualizing Smoking Behaviour over Time: A Smoking Journey from Pleasuring to Suffering. Turkish Online Journal of Qualitative Inquiry, 3 (1), 1-19.

[27] Glaser, B. G. Strauss, A. L. (1967). The Discovery of Grounded Theory: Strategies for Qualitative Research. ed. Aldine Transaction: Chicago.

[28] Prochaska, J.O. \& DiClemente, C.C. (2005). The transtheoretical approach. In J.C. Norcross \& M.R. Goldfried (Eds.), Handbook of psychotherapy integration 2nd Ed. (pp. 147-171). New York: Oxford U. Press.

[29] Blumer, H., Symbolic interationism: Perspective and method. ed. Prentice-Hall: NJ, 1969.

[30] Prochaska, J. O. DiClemente, C. C. (1983). Stages and processes of self-change of smoking: Toward an integrative model of change. Journal of Consulting and Clinical Psychology, 51(3), 390-395. doi: 10.1037/0022-006X.51.3.390.

[31] DiClemente, C. C. (2006) Addiction And Change: How Addictions Develop And Addicted People Recover. ed. Guilford Press: New york.

[32] Prochaska, J. O. Norcross, J. C. (2009). Systems of Psychotherapy: A Transtheoretical Analysis. 7 ed. Brooks/Cole: Pacific Grove.

[33] Rotter, J. B. (1954). Social learning and clinical psychology. ed. Prentice-Hall: 'Vol.' p.

[34] Mead, G., Mind, Self, and Society. ed. University of Chicago Press: Chicago, 1934 'Vol.' p.

[35] Castrucci, B. C. Gerlach, K. K. Kaufman, N. J. Orleans, C. T. (2002). Adolescents' acquisition of cigarettes through noncommercial sources. Journal of Adolescent Health, 31(4), 322-326. doi:10.1016/S1054-139X(02)00393-2.

[36] Piko, B. F. Bak, J. Gibbons, F. X. (2007). Prototype perception and smoking: Are negative or positive social images more important in adolescence? Addictive Behaviors, 32(8), 1728-1732. doi: 10.1016/j.addbeh.2006.12.003.

[37] Weinstein, N. D. (1989). Effects of personal experience on self-protective behavior. Psychological Bulletin, 105(1), 31-50. doi: 10.1037/0033-2909.105.1.31. 